\title{
Chemical composition and antimicrobial activity of hydrodistilled oil from juniper berries
}

\author{
Soraia Falcão ${ }^{\mathrm{a}}$, Isabel Bacém ${ }^{\mathrm{b}}$, Getúlio Igrejas ${ }^{\mathrm{b}}$, Pedro J. Rodrigues ${ }^{\mathrm{c}}$, Miguel Vilas-Boas ${ }^{\mathrm{a}}$, \\ Joana S. Amaral ${ }^{\mathrm{a}, \mathrm{d}, *}$ \\ ${ }^{a}$ Centro de Investigação de Montanha (CIMO), Instituto Politécnico de Bragança, Campus de Santa Apolónia, 5300-253 Bragança, Portugal \\ ${ }^{\mathrm{b}}$ ESTiG, Instituto Politécnico de Bragança, Portugal \\ ${ }^{\mathrm{c}}$ Research Centre in Digitalization and Intelligent Robotics (CeDRI), Instituto Politécnico de Bragança, Campus de Santa Apolónia, $5300-253$ Bragança, Portugal \\ d REQUIMTE-LAQV, Faculdade de Farmácia, Universidade do Porto, Rua de Jorge Viterbo Ferreira, 228, 4050-313 Porto, Portugal
}

\section{A R T I C L E I N F O}

\section{Keywords:}

Juniperus communis

Essential oil

GC-MS

Antimicrobial activity

Oxygenated sesquiterpenes

\begin{abstract}
A B S T R A C T
This study aimed at investigating the chemical composition and in vitro antimicrobial activity of juniper (Juniperus communis L.) berries essential oils (EOs), including commercial samples as well as the oil hydrodistilled from berries grown in Portugal, for which few information is available in the literature. The analysis was performed by gas chromatography coupled to mass spectrometry detection (GC/MS) allowing the identification of a total of 97 compounds. The EOs showed different chemical profiles with only one being according to the European Pharmacopoeia 8 requirements. The laboratory-hydrodistilled EO was characterized by its high content in $\alpha$-pinene (41.6\%), followed by $\beta$-pinene (27.6\%) and limonene (6.4\%), commercial EO1 by $\alpha$-pinene (31.1\%), $\beta$-myrcene $(16.3 \%)$ and sabinene $(7.5 \%)$ and commercial EO2 by $\delta$-cadinene $(16.0 \%), \alpha$-pinene $(12.2 \%)$ and sabinene $(9.4 \%)$. The distinct chemical profiles were also evidenced by principal components analysis (PCA), with a clear separation of the evaluated EOs. One of the commercial samples, showed the presence of propachlor, a banned herbicide in the European Union. All the EOs showed relevant antimicrobial activity as they presented microbicidal activity against Candida albicans and at least six of the ten tested bacteria. Commercial EO2 showed a higher biological activity, as it was active against all tested microorganisms, which could be related to its higher content in sesquiterpenes, in particular those oxygenated. Overall, results support the use of Juniper communis L. berries EO as an antiseptic in traditional medicine and highlight its potential as a biopreservative that could be used in different industries.
\end{abstract}

\section{Introduction}

Essential oils (EOs) are highly complex mixtures of volatile compounds that are biosynthesized by plants to exert diverse ecological functions, such as acting as defensive substances against microorganisms and herbivores (Bakkali et al., 2008). Since ancient times, EOs have been used in traditional medicine for their various properties including spasmolytic, anti-inflammatory, antioxidant and antimicrobial activities (Lang and Buchbauer, 2012). Additionally, due to their generally pleasant odor and/or flavour, several EOs are currently required in significant amounts by different industries such as cosmetic, perfume, pharmaceutical and food industries (Raut and Karuppayil, 2014).

Recently, consumers are becoming increasingly concerned regarding the use of synthetic preservatives to extend the shelf life of foods and cosmetics. Therefore, there has been a renewed interest regarding the possibility of using plant essential oils as biopreservatives in such products, as some have been shown to possess strong antimicrobial activity against a wide range of bacteria (Burt, 2004; KunickaStyczynska et al., 2009; Silva et al., 2013; Sung et al., 2013; Seow et al., 2014). Currently, according to the US Federal Regulation 21CFR182.20, several EO formulations are considered in the category of Generally Recognized as Safe (GRAS) for their intended used, among which juniper oil is included (U.S. Code of Federal Regulations, 2017). Juniper (Juniperus communis L.) is a plant worldwide spread belonging to the Cypress family (Cupressaceae) that has been used along the history for many purposes, including in traditional medicine, in gastronomy as a spice and as a natural ingredient in cosmetic, pharmaceutical and food industries. Juniper berries is one of the few spices

\footnotetext{
* Corresponding author at: Centro de Investigação de Montanha (CIMO), Instituto Politécnico de Bragança, Campus de Santa Apolónia, 5300-253 Bragança, Portugal.

E-mail address: jamaral@ipb.pt (J.S. Amaral).
} 
originated from cold climates, being used as a condiment to confer a particular aroma and taste to game meat dishes traditionally cooked in some European regions, such as in northern Scandinavia and in the northeast of Portugal. They are also used in the aromatization of traditional alcoholic beverages and in the production of gin, the most popular juniper-based spirit. According to the European legislation (Council Regulation EEC 1576/89, 1989), the main flavour in the "Distilled gin" class should come from juniper berries. Additionally, since ancient times juniper berries have also been used in folk medicine for its stomachic, diuretic, antiseptic and antirheumatic properties to treat dyspepsia, cystitis, arthritis, gout and other inflammations (Yarnell, 2002; Sela et al., 2011). Its diuretic effect, in particular, has been attributed to the presence of terpinen-4-ol (EMA, 2011; Sela et al., 2011). Juniper berries are inscribed in several Pharmacopoeias, including the 8th edition of the European Pharmacopoeia (Ph. Eur. 8), and are the source of juniper oil, which is also inscribed in the same Pharmacopoeia. The characteristic composition of the essential oil obtained by steam distillation from the ripe, non-fermented berry cones of Juniperus communis L. is described on the monograph Iuniperi aetheroleum, which defines the following requirements: $20-50 \%$ of $\alpha$-pinene, $1-35.5 \%$ of myrcene, $<20 \%$ of sabinene, $2-12 \%$ of limonene, $1-12 \%$ of $\beta$-pinene, $<7 \%$ of trans-(E)-caryophyllene, $0.5-10 \%$ of terpinen-4ol, $<2 \%$ of bornyl acetate and $<1 \%$ of $\alpha$-phellandrene. Previous studies carried out on EOs extracted by hydrodistillation from juniper berries of diverse geographical origin, including Greece, Italy, Spain, Serbia, Kosovo, Algeria, Lithuania, Estonia, Macedonia and Slovakia, showed a noteworthy variation both on the qualitative and quantitative profile (Chatzopoulou and Katsiotis, 1993; Falasca et al., 2016; Fejér et al., 2018; Foudil-Cherif and Yassaa, 2012; Glišić et al., 2007; Hajdari et al., 2015; Lo[zbreve]ienè et al., 2010; Orav et al., 2010; Sela et al., 2011; Vichy et al., 2007). While $\alpha$-pinene was consistently the major compound in most EOs (although presenting a wide variation of content, ranging from $13.4 \%$ to $77.4 \%$ ), a higher variability was found regarding the other compounds present at higher contents. In this regard, the second most abundant compound was most frequently sabinene or $\beta$-myrcene, although for some EOs were $\beta$-phellandrene, terpinen-4-ol, $\alpha$-pinene, germacrene D or $\delta$-cadinene. In addition, the variability on the chemical composition of the EOs extracted from juniper berries was also evidenced by the fact that several did not comply with Ph. Eur. 8 requirements (Angioni et al., 2003; Chatzopoulou and Katsiotis, 1993; Falasca et al., 2016; Foudil-Cherif and Yassaa, 2012; Lo [zbreve]iené et al., 2010; Matović et al., 2011; Orav et al., 2010; Vichy et al., 2007). This noteworthy variation among the qualitative and quantitative composition can be ascribed to several factors that are known to influence the chemical composition of plant EOs, such as environmental conditions (climate, soil composition, etc), harvesting period/maturation of the berries and extraction method, among others (Fejér et al., 2018). While several reports can be found in the literature regarding the analysis of the essential oil extracted from juniper berries using a Clevenger type apparatus, few information is found on the chemical composition of commercially available oils (Filipowicz et al., 2003; Höferl et al., 2014; Falasca et al., 2016) Additionally, there is a scarcity of data regarding the chemical composition of juniper EO obtained from wild berries grown in Portugal. Therefore, in this work the chemical composition of three different juniper berries essential oils, namely one obtained on the laboratory by hydrodistillation from juniper berries grown in Portugal and two commercially acquired, was evaluated and compared. Considering that the antimicrobial/antiseptic activity is one of the main bioactive properties described for juniper berries EO, in this work, the antimicrobial activity against several pathogenic and food-spoiling bacteria and one yeast was further assessed, in view of its potential use as a biopreservative.

\section{Materials and methods}

\subsection{Samples}

Dried and mature berries of Juniperus communis L. were acquired in 2016 from a Portuguese supplier (Alma d'Flor, Almada, Portugal; the berries were collected in the wild, in the center region of Portugal in 2016, according to the supplier). The berries were used for essential oil extraction by hydrodistillation in a Clevenger apparatus in accordance with the description of the European Pharmacopoeia (1996). Briefly, grounded berries $(50 \mathrm{~g})$ were placed in a round-bottom flask with $500 \mathrm{~mL}$ of distilled water and the mixture was boiled during $3 \mathrm{~h}$. The essential oil was separated from the water and recovered directly without adding any solvent. After being collected, the oil was dried over anhydrous sodium sulfate and stored at $-20^{\circ} \mathrm{C}$ until being analyzed. Additionally, two commercial essential oils from juniper berries, both labelled as being from $J$. communis berries, were tested in this study, one obtained from the same herbal shop of the berries (Alma d'Flor, Portugal; obtained by hydrodistillation according to the supplier) designated as commercial EO1, and the other from a Portuguese distributor (Dias e Beltrame, Portugal; no information was available regarding extraction method used) designated as commercial EO2.

\subsection{GC-MS analysis}

The GC-MS unit consisted on a Perkin Elmer Perkin Elmer system (GC Clarus ${ }^{\circledast} 580$ GC module and Clarus ${ }^{\circledR}$ SQ 8 S MS module) gas chromatograph, equipped with DB-5 MS fused-silica column ( $30 \mathrm{~m} \times 0.25 \mathrm{~mm}$ i.d., film thickness $0.25 \mu \mathrm{m}$; J \& W Scientific, Inc.), and interfaced with a Perkin-Elmer Turbomass mass spectrometer (software version 6.1.0, Perkin Elmer, Shelton, CT, USA). Oven temperature was programmed, $45-175^{\circ} \mathrm{C}$, at $3{ }^{\circ} \mathrm{C} \cdot \mathrm{min}^{-1}$, subsequently at $15^{\circ} \mathrm{C} \mathrm{min}^{-1}$ up to $300^{\circ} \mathrm{C}$, and then held isothermal for $10 \mathrm{~min}$; injector temperature, $280^{\circ} \mathrm{C}$ and the injection volume of $1 \mu \mathrm{L}$. The transfer line temperature was $280^{\circ} \mathrm{C}$; ion source temperature, $220^{\circ} \mathrm{C}$; carrier gas, helium, adjusted to a linear velocity of $30 \mathrm{~cm} \mathrm{~s}^{-1}$; split ratio, 1:40; ionization energy, $70 \mathrm{eV}$; scan range, 40-300 u; scan time, $1 \mathrm{~s}$. Identifications were based on the comparison of the obtained spectra with those of the NIST 2011 mass spectral library and were confirmed using linear retention indices determined from the retention times of an n-alkane (C7-C40) mixture analyzed under identical conditions, with comparison with published data (Adams, 2007), and when possible with commercial standard compounds.

Compounds were quantified as area percentages of total volatiles using the relative values directly obtained from peak total ion current (TIC). Analysis were performed in triplicate.

\subsection{Antimicrobial activity}

The three essential oils were individually tested against 10 different bacterial strains and 1 yeast, namely Bacillus cereus (NCTC 10,320), Bacillus subtilis (ATCC 6633), Enterobacter aerogenes (ATCC 13,048), Enterococcus faecalis (ATCC 33,186), Escherichia coli (ATCC 10,536), Klebsiella pneumoniae (ATCC 13,883), Proteus mirabilis (ATCC 14,153), Pseudomonas aeruginosa (ATCC 27,853), Salmonella typhimurium (ATCC 14,028), Staphylococcus aureus (ATCC 29,213) and the yeast Candida albicans (ESAB collection). The antimicrobial activity was determined by the broth macrodilution method, based on the methodology described by the Clinical and Laboratorial Standards Institute (CLSI, 2009) with some modifications. Briefly, bacterial suspensions were prepared in Mueller-Hinton broth (MHB) for bacteria or in Yeast Extract Peptone Dextrose broth (YPD) for the yeast, from 24-hour cultures in nutrient agar for bacteria or Sabouraud dextrose agar for the yeast, by adjusting to $0.5 \mathrm{McF}$ arland turbidity standard followed by dilution to approximately $5 \times 10^{5} \mathrm{CFU} / \mathrm{mL}$. The essential oil was subjected to twofold serial dilution with MHB added with $0.5 \%$ Tween $80(\mathrm{v} / \mathrm{v})$ in 
sterile glass test tubes. Each test tube, containing the same final volume with different concentration of essential oil, was added with the same volume of bacterial suspension $(1 \mathrm{~mL})$, obtaining a final concentration of essential oil ranging from $25 \mu \mathrm{LmL}^{-1}$ to $0.39 \mu \mathrm{LL}^{-1}$ (corresponding to $2.5 \%-0.039 \%, \mathrm{v} / \mathrm{v}$ ). A blank and negative control were prepared by adding only the inoculum and culture media to MHB for the bacteria or YPD for the yeast added with $0.5 \%$ Tween $80(\mathrm{v} / \mathrm{v})$. Different antibiotics were used as positive control, namely ampicillin and imipenem for Gram-negative bacteria, and ampicillin for Grampositive bacteria. After incubation at $37^{\circ} \mathrm{C}$ for $24 \mathrm{~h}$, the minimum inhibitory concentration (MIC) was determined as the lowest concentration of the essential oil inhibiting visible bacterial growth. To determine the minimum bactericidal concentration (MBC), a loopful of sample from each test tube was sub-cultured in nutrient agar plates and again incubated at $37^{\circ} \mathrm{C}$ for bacteria or $30^{\circ} \mathrm{C}$ for the yeast, for $24 \mathrm{~h}$. The minimum bactericidal concentration (MBC) and minimum fungicidal concentration (MFC) was defined as the concentration of essential oil able to kill all bacteria or yeast, respectively, in the inoculum, translated in the absence of growth after sub-culturing on a medium without antibiotics or antifungal agent. The MIC, MBC or MFC was determinate at least in duplicate for each oil and microorganism.

\subsection{Statistical analysis}

Principal component analysis (PCA) was applied to check the linear separability of data and detect the most important variables (chemical compounds identified in juniper berries essential oils) that are participating on the data variance. A scatter plot where the data is projected on the two principal components was further obtained. Overall, 97 variables corresponding to the essential oil components of the three evaluated samples were used in PCA. The PCA and the construction of the correspondent biplot was performed using the Python package scikit-learn: machine learning, version 0.19.1.

\section{Results and discussion}

\subsection{Chemical composition}

The results obtained for the chromatographic analysis of juniper berries EOs are presented on Table 1, where compounds are listed according to their order of elution (Fig. 1). GC-MS analysis enabled the identification of $99.2 \%-99.9 \%$ of the compounds, corresponding to a total of 97 identified compounds, namely 64 and 65 in the two commercial EOs and 44 in the laboratory-hydrodistilled oil. In general, the chemical composition of the three evaluated oils differed both qualitatively and quantitatively (Fig. 1). The hydrodistilled EO, extracted in the laboratory using a Clevenger apparatus, presented $\alpha$-pinene as major component $(41.6 \%)$, followed by $\beta$-pinene $(27.6 \%)$, limonene (6.4\%), $\beta$-myrcene (5.7\%) and trans-pinocarveol (1.9\%), therefore not being in compliance with Eur. Ph. 8 monography due to the high content of $\beta$-pinene $(>12 \%)$. In general, the sample of EO obtained from Portuguese juniper berries presented a distinct profile when compared with data reported in the literature for juniper berries with different geographical origins. One of the most marked differences concerns the content of $\beta$-pinene and sabinene, which were very high and very low, respectively, when compared with previous data (Angioni et al., 2003; Foudil-Cherif and Yassaa, 2012; Glišić et al., 2007; Matović et al., 2011). However, considering only the qualitative profile, the Portuguese berries presented some similarities with juniper berries from Kosovo, in terms of their major components (Haziri et al., 2013). By the contrary, the chemical composition was very different from the one previously reported for juniper berries collected in the central region of Portugal (Cavaleiro et al., 2006) that presented $\beta$-phellandrene and $\alpha$-terpinyl acetate among the major compounds, those being absent in the herein evaluated sample. The observed differences can be attributed to a range of different factors, namely the geographical origin of the berries (with the inherent differences on climatic conditions and soil characteristics), the collection year, extraction method, but also to genetic factors since $J$. communis is known to include three closely related subspecies: communis, hemisphaerica (C. Presl) Nyman and alpina (Suter) Čelak (also known as nana or saxatilis) (Franco, 1986). This can be an important aspect because different chemotypes have already been described to occur inside the same species for other aromatic and/or medicinal plants (Haghighi et al., 2018).

Commercial EO1, acquired from an herbal shop, was mainly constituted by $\alpha$-pinene (31.1\%), $\beta$-myrcene (16.3\%), sabinene $(7.5 \%)$, limonene (6.2\%) and $\beta$-pinene (3.7\%) (Table 1 ) and was the only one that fully complied with the requirements of the Eur. Ph. 8 monography. Although the total number of identified compounds was similar for both commercial samples, commercial EO2 evidenced a very distinct profile, presenting as main compounds $\delta$-cadinene $(16.0 \%), \alpha$ pinene $(12.2 \%)$, sabinene $(9.4 \%), \beta$-pinene $(7.7 \%)$ and $\gamma$-cadinene (6.3\%). This EO was not according to Eur. Ph. 8 since the levels of $\alpha$ pinene, $\beta$-myrcene and limonene were lower than the required minimum content (Table 1). The chemical profile of this sample was somehow uncommon due to the unusual content of some compounds, such as the very low level of $\beta$-myrcene $(0.9 \%)$ and the considerably high content of $\delta$-cadinene (16.0\%) and $\gamma$-cadinene (6.3\%). However, the identification of $\delta$-cadinene as one of the five major components in juniper berries EO has been previously described in oils obtained from commercial berries from Spain (Vichy et al., 2007) and from Serbia (Matović et al., 2011; Vasilijević et al., 2018), even though the reported levels were slightly lower $(5.2 \%$ to $10.7 \%)$. As mentioned, this uncommon profile can be related to the origin of the berries (geographical and/or genetic). Nevertheless, considering the low content of $\alpha$-pinene and $\beta$-myrcene, and slightly high of terpinen-4-ol, one cannot exclude the possibility of other juniper materials, such as the needles (leaves), being used in the production of this oil. Angioni et al. (2003) studied the chemical composition of the EO hydrodistilled from the leaves, ripe and unripe berries of $J$. communis spp. communis and found that the $\alpha$ pinene and $\beta$-myrcene content of the leaves $(6.4 \%$ and $2.6 \%$, respectively) was much lower than that of the berries $(52.3-52.9 \%$ and $8.1-15.3 \%$, respectively), while the opposite was observed for terpinen$4-$ ol $(10.7 \%$ in the leaves vs. $1.1-1.5 \%$ in the berries). Similar results were reported for the EO of J. communis needles from Algeria (Dahmane et al., 2016) and from the needles of the subspecies alpina collected in Portugal (Cabral et al., 2012). Among the three oils, commercial EO2 was the one that presented the higher content of terpinene-4-ol. As mentioned, this compound is thought to exert diuretic activity through an irritative action on the kidney tissue, therefore supporting the therapeutic value of juniper berries as a urology remedy (Stanić et al., 1998; EMA, 2011). Another relevant aspect in commercial EO2 concerns the identification of propachlor, an herbicide banned in the European Union since September 2008, although plant protection products containing propachlor could remain available until 18 months from the adoption of the decision (Commission Decision, 2008/742/ EC). Despite concerns to the environment and toxicity to birds, mammals and earthworms (European Commission Health \& Consumer Directorate-General SANCO/1350/08), the use of this herbicide is still allowed in China, having an approved maximum residue limit for rice of $0.05 \mathrm{mg} / \mathrm{kg}$ (China Food and Drug Administration, 2016). Recently, this herbicide was detected on pickling cucumbers produced in Brazil despite not being included in the list of approved substances by the Brazilian Agency ANVISA (Neto and Gonçalves, 2016). Regardless of being banned in Europe, a metabolite of this herbicide (propachlor oxanilic acid) was found in the urine of 8 pregnant women that participated in a EC-funded project conducted from January 2012-December 2015 in Spain and Slovakia (López et al., 2016). In the present work, neither the origin of commercial EO2 or the juniper berries used in its production is known.

To verify whether any of the evaluated samples could be grouped according to their chemical composition, PCA was applied. PCA 
Table 1

Composition of Juniperus communis essential oils (commercial and wild berries' hydrodistilled oils).

\begin{tabular}{|c|c|c|c|c|c|c|c|}
\hline \multirow[t]{2}{*}{ Peak number } & \multirow[t]{2}{*}{ Compound } & \multirow[t]{2}{*}{$\mathrm{RT}(\min )$} & \multirow[t]{2}{*}{$\mathrm{LRI}^{a}$} & \multirow[t]{2}{*}{$\mathrm{LRI}^{b}$} & \multicolumn{3}{|c|}{ Juniper berries EO (relative \%) ${ }^{d}$} \\
\hline & & & & & $\begin{array}{l}\text { Commercial } \\
1\end{array}$ & $\begin{array}{l}\text { Commercial } \\
2\end{array}$ & Hydrodistilled \\
\hline 1. & Tricyclene & 6.370 & 917 & 921 & $0.099 \pm 0.003$ & - & $0.157 \pm 0.001$ \\
\hline 2. & $\alpha$-Thujene & 6.560 & 922 & 924 & $1.35 \pm 0.12$ & $0.50 \pm 0.03$ & $0.54 \pm 0.07$ \\
\hline 3. & $\alpha$-Pinene & 6.950 & 934 & 932 & $31.4 \pm 0.6$ & $12.16 \pm 0.27$ & $41.64 \pm 0.85$ \\
\hline 4. & Camphene & 7.300 & 944 & 946 & $0.42 \pm 0.04$ & $0.114 \pm 0.001$ & $1.308 \pm 0.003$ \\
\hline 5. & Thuja-2,4(10)-diene & 7.420 & 947 & 953 & $0.13 \pm 0.01$ & - & $0.069 \pm 0.001$ \\
\hline 6. & Sabinene & 8.190 & 969 & 969 & $7.55 \pm 0.20$ & $9.37 \pm 0.09$ & $0.309 \pm 0.001$ \\
\hline 7. & $\beta$-Pinene & 8.313 & 973 & 974 & $3.68 \pm 0.07$ & $7.75 \pm 0.15$ & $27.63 \pm 0.22$ \\
\hline 8. & Myrcene & 8.940 & 990 & 988 & $16.5 \pm 0.7$ & $0.94 \pm 0.04$ & $5.71 \pm 0.18$ \\
\hline 9. & 2-Carene & 9.065 & 994 & 1001 & - & $0.053 \pm 0.001$ & - \\
\hline 10. & $\alpha$-Phellandrene & 9.363 & 1002 & 1002 & $0.07 \pm 0.01$ & $0.078 \pm 0.004$ & - \\
\hline 11. & 3-Carene & 9.450 & 1004 & 1008 & $0.12 \pm 0.01$ & $0.017 \pm 0.001$ & $0.47 \pm 0.03$ \\
\hline 12. & 1,4-Cineole & 9.730 & 1011 & 1012 & - & - & $0.082 \pm 0.001$ \\
\hline 13. & $\alpha$-Terpinene & 9.783 & 1012 & 1014 & $0.43 \pm 0.03$ & $0.73 \pm 0.02$ & - \\
\hline 14. & p-Cymene & 10.120 & 1020 & 1020 & $0.60 \pm 0.02$ & $3.35 \pm 0.30$ & $1.15 \pm 0.02$ \\
\hline 15. & Limonene & 10.380 & 1026 & 1024 & $6.25 \pm 0.04$ & $1.73 \pm 0.10$ & $6.42 \pm 0.31$ \\
\hline 16. & 1,8-Cineole (eucalyptol) & 10.448 & 1027 & 1026 & - & $0.229 \pm 0.002$ & $0.047 \pm 0.001$ \\
\hline 17. & trans- $\beta$-Ocimene & 10.623 & 1032 & 1032 & $0.16 \pm 0.02$ & $0.058 \pm 0.001$ & $0.208 \pm 0.004$ \\
\hline 18. & $\gamma$-Terpinene & 11.500 & 1052 & 1054 & $0.75 \pm 0.04$ & $2.10 \pm 0.04$ & - \\
\hline 19. & cis-Sabinene hydrate & 12.058 & 1065 & 1065 & $0.17 \pm 0.01$ & $0.207 \pm 0.001$ & - \\
\hline 20. & Terpinolene & 12.653 & 1079 & 1086 & $0.75 \pm 0.02$ & $0.82 \pm 0.02$ & - \\
\hline 21. & $\alpha$-Pinene oxide & 13.231 & 1093 & $1095^{c}$ & - & $0.066 \pm 0.001$ & $1.19 \pm 0.03$ \\
\hline 22. & trans-Sabinene Hydrate & 13.406 & 1097 & 1098 & - & $0.169 \pm 0.001$ & - \\
\hline 23. & Linalool & 13.420 & 1097 & $1098^{c}$ & $0.42 \pm 0.01$ & - & - \\
\hline 24. & trans-2-Caren-4-ol & 13.773 & 1105 & & - & - & $1.39 \pm 0.01$ \\
\hline 25. & cis-p-Menth-2-en-1-ol & 14.438 & 1120 & 1118 & $0.0826 \pm 0.0011$ & - & - \\
\hline 26. & $\alpha$-Campholenal & 14.526 & 1122 & 1122 & $0.64 \pm 0.15$ & - & $0.30 \pm 0.01$ \\
\hline 27. & cis-Limonene oxide & 14.771 & 1127 & 1132 & - & - & $0.104 \pm 0.005$ \\
\hline 28. & trans-Pinocarveol & 15.120 & 1135 & 1135 & $0.62 \pm 0.02$ & $0.097 \pm 0.001$ & $1.89 \pm 0.04$ \\
\hline 29. & cis-Verbenol & 15.226 & 1137 & 1137 & $0.25 \pm 0.01$ & - & $0.078 \pm 0.001$ \\
\hline 30. & trans-p-Menth-2-en-1-ol & 15.261 & 1138 & $1142^{c}$ & - & $0.22 \pm 0.01$ & - \\
\hline 31. & trans-Verbenol & 15.440 & 1142 & $1144^{c}$ & $0.89 \pm 0.04$ & $0.101 \pm 0.002$ & $1.07 \pm 0.04$ \\
\hline 32. & trans-Pinocamphone & 15.979 & 1153 & 1158 & $0.13 \pm 0.01$ & - & $0.10 \pm 0.01$ \\
\hline 33. & Pinocarvone & 16.066 & 1155 & 1160 & $0.115 \pm 0.003$ & - & $0.44 \pm 0.01$ \\
\hline 34. & Terpinen-4-ol & 16.990 & 1176 & 1174 & $2.00 \pm 0.09$ & $5.43 \pm 0.07$ & $0.16 \pm 0.01$ \\
\hline 35. & p-Cymen-8-ol & 17.326 & 1183 & 1179 & $0.17 \pm 0.02$ & $0.22 \pm 0.01$ & $0.217 \pm 0.001$ \\
\hline 36. & Myrtenal & 17.571 & 1188 & $1193^{c}$ & $0.20 \pm 0.01$ & $0.014 \pm 0.001$ & $0.79 \pm 0.06$ \\
\hline 37. & $\alpha$-Terpineol & 17.680 & 1191 & $1194^{c}$ & $0.68 \pm 0.05$ & $0.50 \pm 0.01$ & - \\
\hline 38. & Myrtenol & 17.729 & 1192 & $1196^{c}$ & - & - & $1.38 \pm 0.03$ \\
\hline 39. & Verbenone & 18.149 & 1201 & $1204^{c}$ & $0.28 \pm 0.01$ & $0.028 \pm 0.001$ & $0.32 \pm 0.01$ \\
\hline 40. & trans-Carveol & 18.744 & 1214 & 1215 & $0.19 \pm 0.01$ & - & $0.220 \pm 0.004$ \\
\hline 41. & Citronellol & 19.234 & 1225 & 1223 & $0.29 \pm 0.01$ & - & - \\
\hline 42. & cis-Carveol & 19.339 & 1228 & $1228^{c}$ & - & - & $0.050 \pm 0.001$ \\
\hline 43. & Thymol, methyl ester & 19.584 & 1233 & 1232 & - & $0.22 \pm 0.01$ & $0.03 \pm 0.04$ \\
\hline 44. & Carvone & 20.022 & 1243 & 1239 & $0.025 \pm 0.003$ & - & $0.09 \pm 0.01$ \\
\hline 45. & Citronellic acid, methyl ester & 20.547 & 1252 & & $0.26 \pm 0.01$ & - & - \\
\hline 46. & Bornyl acetate & 21.614 & 1278 & $1284^{c}$ & $0.49 \pm 0.06$ & $0.157 \pm 0.002$ & $0.149 \pm 0.004$ \\
\hline 47. & Anethole & 21.719 & 1280 & $1287^{c}$ & - & $0.42 \pm 0.01$ & - \\
\hline 48. & 2-Undecanone & 22.122 & 1289 & $1291^{c}$ & $0.19 \pm 0.01$ & - & - \\
\hline 49. & 1,4-Dihydroxy-p-menth-2-ene & 22.122 & 1289 & & - & $0.170 \pm 0.002$ & - \\
\hline 50. & Isocarveol & 22.332 & 1294 & $1286^{c}$ & - & - & $0.081 \pm 0.002$ \\
\hline 51. & Carvacrol & 22.472 & 1297 & 1298 & - & $0.044 \pm 0.002$ & - \\
\hline 52. & $\delta$-Elemene & 23.627 & 1322 & $1325^{c}$ & $0.096 \pm 0.001$ & $0.018 \pm 0.002$ & - \\
\hline 53. & $\alpha$-Cubebene & 24.309 & 1339 & $1341^{c}$ & $0.99 \pm 0.05$ & $0.32 \pm 0.01$ & $0.026 \pm 0.001$ \\
\hline 54. & 8-p-Menthen-1,2-diol & 24.415 & 1341 & & - & - & $0.039 \pm 0.001$ \\
\hline 55. & $\alpha$-Copaene & 25.482 & 1366 & $1367^{c}$ & $0.54 \pm 0.04$ & $0.49 \pm 0.02$ & $0.037 \pm 0.001$ \\
\hline 56. & Propachlor & 26.042 & 1378 & & - & $0.15 \pm 0.01$ & - \\
\hline 57. & $\beta$-Elemene & 26.147 & 1381 & $1383^{c}$ & $0.98 \pm 0.08$ & $0.36 \pm 0.01$ & $0.269 \pm 0.003$ \\
\hline 58. & Longifolene & 26.812 & 1396 & 1407 & $0.10 \pm 0.01$ & - & - \\
\hline 59. & $\alpha$-Cedrene & 27.075 & 1402 & 1410 & - & $0.140 \pm 0.004$ & $0.263 \pm 0.001$ \\
\hline 60. & $\beta$-Caryophyllene & 27.372 & 1409 & 1417 & $3.60 \pm 0.10$ & $0.70 \pm 0.03$ & - \\
\hline 61. & $\beta$-Cedrene & 27.407 & 1410 & 1419 & - & $0.045 \pm 0.001$ & $0.07 \pm 0.01$ \\
\hline 62. & $\beta$-Cubebene & 27.757 & 1418 & $1418^{c}$ & $0.25 \pm 0.35$ & - & - \\
\hline 63. & $\gamma$-Elemene & 27.880 & 1421 & $1433^{c}$ & $2.50 \pm 0.22$ & $0.89 \pm 0.03$ & $0.028 \pm 0.001$ \\
\hline 64. & cis-Thujopsene & 27.932 & 1423 & $1425^{c}$ & - & $0.39 \pm 0.01$ & - \\
\hline 65. & $\alpha$-Bergamotene & 28.002 & 1424 & $1430^{c}$ & - & - & - \\
\hline 66. & $\alpha$-Humullene & 28.860 & 1445 & 1452 & $2.09 \pm 0.02$ & $0.27 \pm 0.01$ & - \\
\hline 67. & $\beta$-Farnesene & 28.983 & 1448 & 1456 & $0.81 \pm 0.01$ & - & - \\
\hline 68. & epi-Bicyclosesquiphellandrene & 29.122 & 1451 & & - & $0.76 \pm 0.03$ & - \\
\hline 69. & $\gamma$-Muurolene & 29.718 & 1465 & $1465^{c}$ & $0.351 \pm 0.002$ & $1.92 \pm 0.07$ & $0.153 \pm 0.001$ \\
\hline 70. & Germacrene D & 29.963 & 1471 & $1468^{c}$ & $3.35 \pm 0.46$ & - & - \\
\hline 71. & $\beta$-Selinene & 30.208 & 1477 & $1475^{c}$ & $0.39 \pm 0.02$ & - & - \\
\hline
\end{tabular}


Table 1 (continued)

\begin{tabular}{|c|c|c|c|c|c|c|c|}
\hline \multirow[t]{2}{*}{ Peak number } & \multirow[t]{2}{*}{ Compound } & \multirow[t]{2}{*}{ RT (min) } & \multirow[t]{2}{*}{$\mathrm{LRI}^{a}$} & \multirow[t]{2}{*}{$\mathrm{LRI}^{b}$} & \multicolumn{3}{|c|}{ Juniper berries EO (relative \%) ${ }^{d}$} \\
\hline & & & & & $\begin{array}{l}\text { Commercial } \\
1\end{array}$ & $\begin{array}{l}\text { Commercial } \\
2\end{array}$ & Hydrodistilled \\
\hline 72. & $\alpha$-Muurolene & 30.663 & 1488 & $1488^{c}$ & $0.30 \pm 0.03$ & $5.10 \pm 0.19$ & $0.053 \pm 0.001$ \\
\hline 73. & $\gamma$-Cadinene & 31.223 & 1502 & $1508^{c}$ & $0.364 \pm 0.003$ & $6.27 \pm 0.23$ & $0.181 \pm 0.001$ \\
\hline 74. & $\delta$-Cadinene & 31.503 & 1508 & $1515^{c}$ & $1.42 \pm 0.08$ & $16.04 \pm 0.46$ & - \\
\hline 75. & $\alpha$-Cadinene & 32.290 & 1528 & 1537 & - & $1.72 \pm 0.03$ & - \\
\hline 76. & Cadala-1(10),3,8-triene & 32.413 & 1531 & & - & $0.194 \pm 0.004$ & - \\
\hline 77. & Elemol & 32.710 & 1539 & $1541^{c}$ & $0.106 \pm 0.004$ & $5.38 \pm 0.21$ & $0.334 \pm 0.003$ \\
\hline 78. & $\alpha$-Calacorene & 33.218 & 1552 & $1553^{c}$ & - & $0.212 \pm 0.002$ & - \\
\hline 79. & trans-Nerolidol & 33.375 & 1556 & $1554^{c}$ & - & $0.196 \pm 0.001$ & - \\
\hline 80. & Spathulenol & 33.761 & 1565 & 1577 & $0.59 \pm 0.05$ & $0.119 \pm 0.001$ & - \\
\hline 81. & Caryophyllene oxide & 33.918 & 1569 & 1582 & $1.02 \pm 0.10$ & $0.22 \pm 0.01$ & $0.313 \pm 0.004$ \\
\hline 82. & Gleenol & 34.233 & 1577 & 1586 & - & $0.054 \pm 0.001$ & - \\
\hline 83. & Cedrol & 34.916 & 1595 & 1600 & - & $0.198 \pm 0.003$ & $1.33 \pm 0.03$ \\
\hline 84. & Humullene oxide & 34.986 & 1596 & & $0.58 \pm 0.04$ & - & - \\
\hline 85. & epi-Cubenol & 35.721 & 1616 & $1621^{c}$ & $0.19 \pm 0.01$ & $0.45 \pm 0.01$ & - \\
\hline 86. & $\gamma$-Eudesmol & 35.948 & 1622 & 1630 & - & $0.93 \pm 0.03$ & - \\
\hline 87. & $\tau$-Cadinol & 36.263 & 1630 & $1634^{c}$ & $0.095 \pm 0.001$ & $2.77 \pm 0.10$ & $0.050 \pm 0.001$ \\
\hline 88. & $\tau$-Muurolol & 36.368 & 1633 & $1635^{c}$ & $0.13 \pm 0.01$ & $2.04 \pm 0.08$ & $0.038 \pm 0.001$ \\
\hline 89. & Cubenol & 36.473 & 1636 & $1644^{c}$ & $0.07 \pm 0.01$ & - & - \\
\hline 90. & $\beta$-Eudesmol & 36.683 & 1641 & $1645^{c}$ & - & - & $0.077 \pm 0.002$ \\
\hline 91. & $\delta$-Cadinol & 36.788 & 1644 & $1646^{c}$ & $0.275 \pm 0.004$ & $0.68 \pm 0.02$ & - \\
\hline 92. & $\alpha$-Cadinol & 36.893 & 1647 & $1649^{c}$ & $0.18 \pm 0.01$ & $2.63 \pm 0.09$ & $0.17 \pm 0.01$ \\
\hline 93. & 5-Hydroximethyl-1,1,4,6-trimethyl-6-methylenedecahydronaphtalen-2-ol & 39.676 & 1721 & & - & $0.16 \pm 0.01$ & - \\
\hline 94. & Labda-8(20)-12,14-triene & 45.420 & 1916 & & $0.065 \pm 0.005$ & $0.122 \pm 0.001$ & - \\
\hline 95. & Geranyl- $\alpha$-terpinene & 45.784 & 1940 & & $0.090 \pm 0.007$ & - & $0.77 \pm 0.01$ \\
\hline 96. & Verticiol & 46.292 & 1975 & & $0.101 \pm 0.009$ & - & - \\
\hline \multirow[t]{10}{*}{97.} & Abietatriene & 47.115 & 2043 & 2055 & $0.082 \pm 0.005$ & - & - \\
\hline & Total identified & & & & 99.2 & 99.9 & 99.6 \\
\hline & Monoterpene hydrocarbons & & & & 70.4 & 40.1 & 85.7 \\
\hline & Oxygen-containing monoterpenes & & & & 7.5 & 7.7 & 10.1 \\
\hline & Sesquiterpene hydrocarbons & & & & 18.1 & 36.0 & 1.1 \\
\hline & Oxygen-containing sesquiterpenes & & & & 3.2 & 15.8 & 2.3 \\
\hline & Diterpene hydrocarbons & & & & 0.2 & 0.1 & 0.8 \\
\hline & Oxygenated diterpenes & & & & 0.1 & - & - \\
\hline & Others & & & & 0.2 & - & - \\
\hline & Herbicides & & & & - & 0.1 & - \\
\hline
\end{tabular}

${ }^{\mathrm{a}} \mathrm{LRI}$, linear retention index determined on a DB-5 MS fused silica column relative to a series of n-alkanes (C7-C40).

${ }^{b}$ linear retention index reported in literature (Adams, 2007), with the exception of those marked as ${ }^{\mathrm{c}}$ which refers to NIST 2011.

${ }^{d}$ relative $\%$ is given as mean $\pm \mathrm{SD}, n=3$.

transforms the original measured variables (totality of chemical compounds identified in juniper berries essential oils) into a smaller number of new uncorrelated variables (principal components or factors) that adequately summarized the original information. Fig. 2 shows the obtained biplot of component loadings, where it can be observed that the juniper berries EOs were completely separated on three groups by the two principal components. The first principal component (PC1), explaining $73.0 \%$ of data variance, allowed the linear separation of the samples. Commercial EO2 was represented on the negative region of PC1, being characterized by an higher content of $\delta$-cadinene and sabinene and low of $\alpha$-pinene, while the opposite was verified for laboratory-hydrodistilled EO, being represented on the positive region of PC1. The second principal component (PC2), explaining $23.0 \%$ of data variance, allowed the clear separation of commercial EO1 mainly due to its higher content of $\beta$-pinene and lower of $\beta$-myrcene (Fig.2).

\subsection{Antimicrobial activity}

The results obtained for the antimicrobial activity of the essential oils against the tested strains are shown in Table 2. In general, all the tested EOs showed interesting bioactive properties as they presented microbicidal activity against $C$. albicans and at least six of the ten tested bacteria. The tested juniper berries EOs showed to be more active against Gram-positive (MIC, $0.08-0.63 \%$ and MBC, $0.08-1.25 \%$ ) than Gram-negative bacteria (MIC, $0.16-1.25 \%$ and MBC, $0.31-2.5 \%$, with some strains being resistant at the higher tested concentration). Among the tested strains, B. cereus and B. subtilis (MBC, 0.16\%) were the most susceptible bacteria, being sensitive to all tested EOs and showing the lowest MICs (0.08-0.16\% for both bacteria) and MBC $(0.08-0.16 \%$ and $0.16 \%$, respectively). On the other hand, E. aerogenes, $P$. aeruginosa and $S$. typhimurium were the least susceptible, with only one EO being active against these bacteria at the tested concentrations. This is in good agreement with previous studies on the antimicrobial activity of juniper berries EO (Filipowicz et al., 2003; Haziri et al., 2013), as well as with data available in the literature that describe Gram-positive bacteria has being more susceptible to essential oils than Gram-negative bacteria (Burt, 2004; Silva et al., 2013), possibly due to the presence of lipoproteins and lipopolysaccharides in Gram-negative bacteria that form a barrier to hydrophobic compounds (Mann et al., 2000).

While the laboratory-hydrodistilled EO and commercial EO1 did not evidenced bactericidal activity towards 3 and 4 bacteria strains, respectively, all tested bacteria were sensitive to commercial EO2 (Table 2). In light of the differences in chemical composition and the PCA results, that evidenced three distinct groups, it was expected that the three EOs would have different antimicrobial potential. However, commercial EO1 and the hydrodistilled EO presented similar antimicrobial activity while a stronger activity was found for commercial EO2. Table 1 shows that, compared with the other EOs, commercial EO2 presented a considerably higher content of sesquiterpene hydrocarbons (36.0\%) and oxygenated sesquiterpenes (15.8\%), which could 

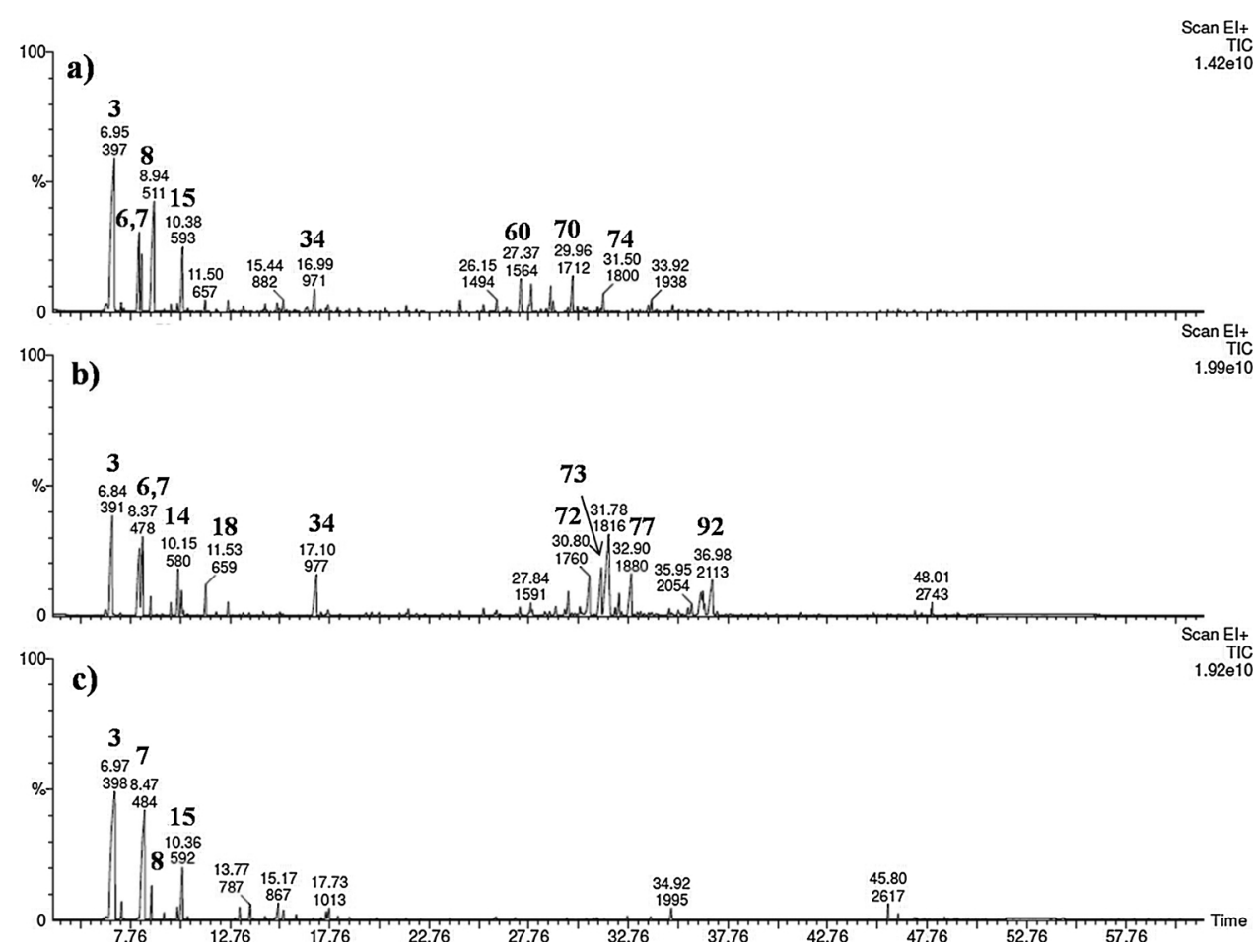

Fig. 1. Gas chromatography-mass spectrometry (GC-MS) profiles of juniper berries essential oil: (A, B) commercial samples and (C) laboratory-hydrodistilled sample. The major compounds are numbered as presented in Table 2.

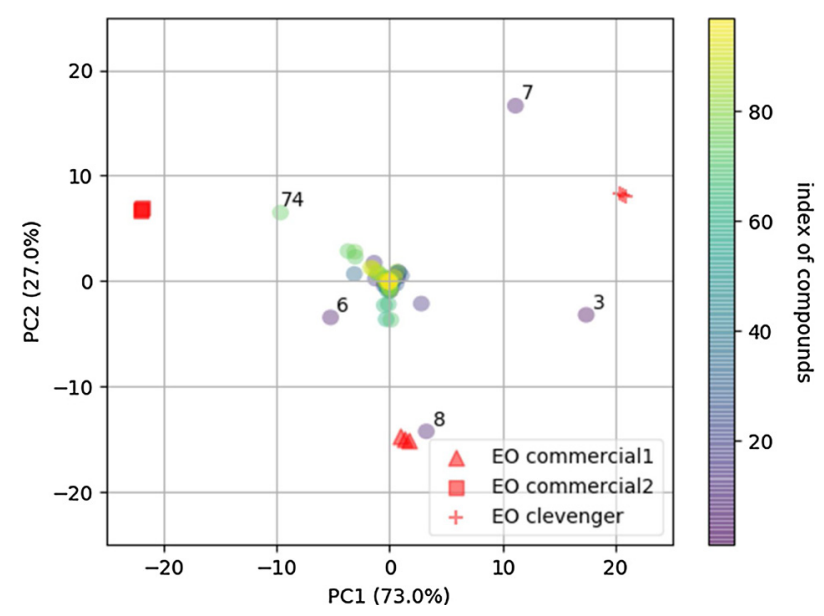

Fig. 2. Principal components analysis (PCA) biplot showing the linear separability of objects (juniper berries essential oils) and major component loadings (evaluated compounds; the index of the compounds is shown on a color scale).

explain its superior activity. However, considering that the content of sesquiterpene hydrocarbons was also much higher in commercial EO1 (18.1\%) than in the hydrodistilled EO (1.1\%), but both EOs showed similar biological activity, the contribution of this class to the overall activity of the oils is probably scarce. Conversely, the obtained results suggest that the class of oxygenated sesquiterpenes largely contribute to the antimicrobial activity of the assayed EOs. This is in good agreement with previous studies that associated sesquiterpene alcohols, such as elemol, $\alpha$ - and $\beta$-eudesmol, to enhanced antimicrobial activity (Sadgrove et al., 2014). Nonetheless, compounds of the other classes, such as monoterpenes hydrocarbons and oxygenated monoterpens, can also play an active role and synergistically contribute to the biological activity of juniper berries EOs (Glišić et al., 2007). Using transmission electron microscopy, Peruč et al. (2018) confirmed the inhibitory effect of juniper EO against Mycobacterium spp. by revealing significant
Table 2

Minimum inhibitory concentration (MIC), minimum bactericidal concentration (MBC) and minimum fungicidal concentration (MFC) of juniper berries essential oils.

\begin{tabular}{|c|c|c|c|c|c|c|}
\hline \multirow[t]{3}{*}{ Microorganism } & & \multicolumn{5}{|c|}{ Essential oil $(\%, v / v)^{a}$} \\
\hline & \multicolumn{2}{|c|}{ Commercial 1} & \multicolumn{2}{|c|}{ Commercial 2} & \multicolumn{2}{|c|}{ Hydrodistilled } \\
\hline & MIC & MBC & MIC & MBC & MIC & MBC \\
\hline \multicolumn{7}{|l|}{ Gram positive } \\
\hline Bacillus cereus & 0.08 & 0.16 & 0.08 & 0.08 & 0.16 & 0.16 \\
\hline Bacillus subtilis & 0.16 & 0.16 & 0.08 & 0.16 & 0.16 & 0.16 \\
\hline Staphylococcus aureus & 0.63 & 1.25 & 0.16 & 0.31 & 0.16 & 0.31 \\
\hline \multicolumn{7}{|l|}{ Gram negative } \\
\hline Escherichia coli & 0.31 & 0.63 & 0.31 & 0.31 & 1.25 & 2.5 \\
\hline Enterococcus faecalis & 0.31 & 0.63 & 0.31 & 0.31 & 0.31 & 0.63 \\
\hline Enterobacter aerogenes & $-\mathrm{b}$ & $-^{c}$ & 1.25 & 2.5 & $-\mathrm{b}$ & $c^{c}$ \\
\hline Klebsiella pneumonia & 1.25 & 2.5 & 0.16 & 0.63 & 0.31 & 1.25 \\
\hline Proteus mirabilis & $-\mathrm{b}$ & $-c$ & 0.16 & 0.16 & 0.63 & 1.25 \\
\hline $\begin{array}{c}\text { Pseudomonas } \\
\text { aeruginosa }\end{array}$ & $-{ }^{b}$ & $-{ }^{c}$ & 1.25 & 1.25 & $-\mathrm{b}$ & $-c$ \\
\hline Salmonella typhimurium & $-b$ & $-{ }^{c}$ & 0.63 & 1.25 & $-{ }^{b}$ & $-c$ \\
\hline Yeast & MIC & MFC & MIC & MFC & MIC & MFC \\
\hline Candida albicans & 0.16 & 0.31 & 0.039 & 0.08 & 0.16 & 0.31 \\
\hline
\end{tabular}

${ }^{\text {a }}$ Essential oils were tested in the concentration range of $2.5 \%$ to $0.039 \%(\mathrm{v} /$ v).

b No inhibition was visually observed for the maximum tested concentration $(2.5 \%)$.

${ }^{\mathrm{c}}$ Growth was obtained for the maximum tested concentration (2.5\%).

morphological changes in the cell membrane and cytoplasm, and leakage of intracellular material. This effect could be due to monoterpene hydrocarbons that can easily pass through lipid bilayers and cause damages in the cell. Also, according to previous studies, antimicrobial activity has already been described for some oxygenated monoterpenes, such as terpinen-4-ol and 1,8-cineole (Carson and Riley, 1995). Thus, the higher content of these compounds in commercial EO2 can also contribute to explain its higher antimicrobial activity. 


\section{Conclusions}

The three EOs from juniper berries studied in this work showed distinct profiles and only one presented a composition that fulfilled the requirements of Ph. Eur. 8. The identification of a banned herbicide in one commercial EO together with the large variation on the chemical composition observed between the two commercial oils highlights the importance of quality control/monitoring of EO composition.

Overall results also showed that juniper berries EO have antimicrobial activity against several pathogenic bacteria and C. albicans, with one commercial EO presenting microbicidal activity against all tested microorganisms, including $P$. aeruginosa. This is particularly interesting considering the increasing levels of resistance of this bacteria towards multiple classes of antibiotics. The stronger activity of commercial EO2 can possibly be related to a higher amount of oxygenated sesquiterpenes, such as elemol. The obtained results support the use of the essential oil from Juniper communis L. berries in traditional medicine for its antimicrobial activity and highlight its potential as an interesting biopreservative for different industries.

\section{Acknowledgments}

The authors acknowledge the technical support given by Maria João Afonso (ESTiG, IPB). The authors are grateful to the Foundation for Science and Technology (FCT, Portugal) and FEDER under Programme PT2020 for financial support to CIMO (UID/AGR/00690/2013). Soraia I. Falcão thanks FCT for the Post-Doc grant SFRH/BPD/118987/2016.

\section{References}

Adams, R., 2007. Identification of Essential Oil Components by Gas Chromatography/ Mass Spectrometry. Allured Publishing Corporation, Illinois.

Angioni, A., Barra, A., Russo, M.T., Coroneo, V., Dessiä, S., Cabras, P., 2003. Chemical composition of the essential oils of juniperus from ripe and unripe berries and leaves and their antimicrobial activity. J. Agric. Food Chem. 51, 3073-3078.

Bakkali, F., Averbeck, S., Asssverbeck, D., Idaomar, M., 2008. Biological effects of essential oils - a review. Food Chem. Toxicol. 46, 446-475.

Burt, S., 2004. Essential oils: their antibacterial properties and potential applications in foods-a review. Int. J. Food Microbiol. 94, 223-253.

Cabral, C., Francisco, V., Cavaleiro, C., Gonçalves, M.J., Cruz, M.T., Sales, F., Batista, T., Salgueiro, L., 2012. Essential oil of Juniperus communis subsp. Alpine (Suter) Čelak needles: chemical composition, antifungal activity and cytotoxicity. Phytother. Res. $26,1352-1357$

Carson, C.F., Riley, T.V., 1995. Antimicrobial activity of the major components of the essential oil of Melaleuca alternifolia. J. Appl. Microbiol. 78, 264-269.

Cavaleiro, C., Pinto, E., Gonçalves, M.J., Salgueiro, L., 2006. Antifungal activity of Juniperus essential oils against dermatophyte, Aspergillus and Candida strains. J. Appl. Microbiol. 100, 1333-1338.

Chatzopoulou, P., Katsiotis, S.T. 1993. Study of the essential oil from Juniperus communis "berries" (cones) growing wild in Greece. Planta Med. 59, 554-556.

China Food and Drug Administration, 2016. Retrieved from: National Food Safety Standard - Maximum Residue Limits for Pesticides in Foods (GB 2763-2016) (Accessed in February 2018). https://gain.fas.usda.gov/Recent\%20GAIN \%20Publications/China\%20Releases\%20New\%20Maximum\%20Residue\%20Limits \%20for\%20Pesticides\%20in\%20Food_Beijing_China\%20-\%20Peoples\%20Republic $\% 20$ of_4-28-2017.pdf.

Commission Decision 2008/742/EC concerning the non-inclusion of propachlor in Annex I to Council Directive 91/414/EEC and the withdrawal of authorisations for plant protection products containing that substance. 2008. Official Journal of the European Union, L 251, 39-40.

Council Regulation (EEC) No 1576/89 laying down general rules on the definition, description and presentation of spirit drinks. 1989. Official Journal of the European Union, L 160, 1-17.

Dahmane, D., Dob, T., Chelghoum, C., 2016. Essential oil composition and enantiomeric distribution of some monoterpenoid components of Juniperus communis L. from Algeria. J. Essent. Oil Res. 28, 348-356.

European Medicines Agency (EMA), Committee on Herbal Medicinal Products (HMPC). 2011. Assessment report on Juniperus communis L., pseudofructus. EMA/HMPC/ 441930/2008. Retrieved from http://www.ema.europa.eu/docs/en_GB/document library/Herbal___HMPC_assessment_report/2011/02/WC500102144.pdf (Accessed in January 2018).

European Commission Health \& Consumer Directorate-General SANCO/1350/08. 2008 Review report for the active substance propachlor, Finalised in the Standing Committee on the Food Chain and Animal Health at its meeting on 20 May 2008. Retrieved from http://ec.europa.eu/food/plant/pesticides/eu-pesticides-database/ public $/$ ? event $=$ activesubstance. ViewReview\&id $=224$ (Accessed in February 2018).

Falasca, A., Caprari, C., De Felice, V., Fortini, P., Saviano, G., Zollo, F., Iorizzi, M., 2016. GC-MS analysis of the essential oils of Juniperus communis L. Berries growing wild in the Molise region: seasonal variability and in vitro antifungal activity. Biochem. Syst. Ecol. 69, 166-175.

Fejér, J., Grul'ová, D., Eliašová, A., Kronb, I., De Feo, V., 2018. Influence of environmental factors on content and composition of essential oil from common juniper ripe berry cones (Juniperus communis L.). Plant Biosyst. https://doi.org/10.1080/11263504. 2018.1435577. in press.

Filipowicz, N., Kamiński, M., Kurlenda, J., Asztemborska, M., Ochocka, J.R., 2003. Antibacterial and antifungal activity of juniper berry oil and its selected components. Phytother. Res. 17, 227-231.

Foudil-Cherif, Y., Yassaa, N., 2012. Enantiomeric and non-enantiomeric monoterpenes of Juniperus communis L. and Juniperus oxycedrus needles and berries determined by HS-SPME and enantioselective GC/MS. Food Chem. 135, 1796-1800.

Franco, J.A., 1986. Juniperus L. In: In: Castroviejo, S., Laínz, M., López-González, G., Montserrat, P., Muñoz Garmendia, F., Paiva, J., Villar, L. (Eds.), Flora Iberica 1. CSIC, Madrid, pp. 181-188.

Glišić, S.B., Milojević, S.Ž., Dimitrijević, S.I., Orlović, A.M., Skala, D.U., 2007. Antimicrobial activity of the essential oil and different fractions of Juniperus communis L. and a comparison with some commercial antibiotics. J. Serb. Chem. Soc. 72 (4), 311-320.

Haghighi, T.M., Saharkhiz, M.J., Khosravi, A.R., Fard, F.R., Moein, M., 2018. Essential oil content and composition of Vitex pseudo-negundo in Iran varies with ecotype and plant organ. Ind. Crops Prod. 109, 53-59.

Hajdari, A., Mustafa, B., Nebija, D., Miftari, E., Quave, C.L., Novak, J., 2015. Chemical composition of Juniperus communis L. cone essential oil and its variability among wild populations in Kosovo. Chem. Biodivers. 12 (11), 1706-1717.

Haziri, A., Faiku, F., Mehmeti, A., Govori, S., Abazi, S., Daci, M., Haziri, I., BytyqiDamoni, A., Mele, A., 2013. Antimicrobial properties of the essential oil of Juniperus communis (L.) growing wild in east part of Kosovo. Am. J. Pharmacol. Toxicol. 8 (3), $128-133$.

Höferl, M., Stoilova, I., Schmidt, E., Wanner, J., Jirovetz, L., Trifonova, D., Krastev, L. Krastanov, A., 2014. Chemical composition and antioxidant properties of juniper berry (Juniperus communis L.) essential oil. Action of the essential oil on the antioxidant protection of Saccharomyces cerevisiae model organism. Antioxidants 3, 81-98.

Kunicka-Styczynska, A., Sikora, M., Kalemba, D., 2009. Antimicrobial activity of lavender, tea tree and lemon oils in cosmetic preservative systems. J. Appl. Microbiol. 107, 1903-1911.

Lang, G., Buchbauer, G., 2012. A review on recent research results (2008-2010) on essential oils as antimicrobials and antifungals. A review. Flavour Fragr. J. 27, 13-39.

Lo[zbreve]ienè, K., Labokas, J., Venskutonis, P.R., Maždžierienè, R., 2010. Chromatographic evaluation of the composition of essential oil and $\alpha$-pinene enantiomers in Juniperus communis L. berries during ripening. J. Essent. Oil Res. 22, $453-458$.

López, A., Dualde, P., Yusà, V., Coscollà, C., 2016. Retrospective analysis of pesticide metabolites in urine using liquid chromatography coupled to high-resolution mass spectrometry. Talanta 160, 547-555.

Mann, C.M., Cox, S.D., Markham, J.L., 2000. The outer membrane of Pseudomonas aeruginosa NCTC 6749 contributes to its tolerance to the essential oil of Melaleuca alternifolia (tea tree oil). Lett. Appl. Microbiol. 30, 294-297.

Matović, M., Bojović, B., Jušković, M., 2011. Composition of essential oils from three classes of juniper fruit from Serbia. J. Med. Plants Res. 5 (26), 6160-6163.

Neto, J.V., Gonçalves, P.A.S., 2016. Resíduos de agrotóxicos em pepinos para conserva in natura e industrializados. Hortic. Bras. 34, 126-129.

Orav, A., Kailas, T., Müürisepp, M., 2010. Chemical investigation of the essential oil from berries and needles of common juniper (Juniperus communis L.) growing wild in Estonia. Nat. Prod. Res. 24 (19), 1789-1799.

Peruč, D., Gobin, I., Abram, M., Broznić, D., Svalina, T., Štifter, S., Staver, M.M., Tićac, B. 2018. Antimycobacterial potential of the juniper berry essential oil in tap water. Arh. Hig. Rada Toksikol. 69, 46-54.

Raut, J.S., Karuppayil, S.M., 2014. A status review on the medicinal properties of essential oils. Ind. Crops Prod. 62, 250-264.

Sadgrove, N.J., Telford, I.R.H., Greatrex, B.W., Jones, G.L., 2014. Composition and antimicrobial activity of the essential oils from the Phebalium squamulosum species complex (Rutaceae) in New South Wales, Australia. Phytochemistry 97, 38-45.

Sela, F., Karapandzova, M., Stefkov, G., Kulevanova, S., 2011. Chemical composition of berry essential oils from Juniperus communis L. (Cupressaceae) growing wild in Republic of Macedonia and assessment of the chemical composition in accordance to European Pharmacopoeia. Macedonian Pharm. Bull. 57, 43-51.

Seow, Y.X., Yeo, C.R., Chung, H.L., Yuk, H.-G., 2014. Plant essential oils as active antimicrobial agents. Crit. Rev. Food Sci. Nutr. 54 (5), 625-644.

Silva, N., Alves, S., Gonçalves, A., Amaral, J.S., Poeta, P., 2013. Antimicrobial activity of essential oils from Mediterranean aromatic plants against several foodborne and spoilage bacteria. Food Sci. Technol. Int. 19 (6), 503-510.

Stanić, G., Samaržija, I., Blaževic, N., 1998. Time-dependent diuretic response in rats treated with juniper berry preparations. Phytother. Res. 12, 494-497.

Sung, S.-Y., Sin, L.T., Tee, T.-T., Bee, S.-T., Rahmat, A.R., Rahman, W.A.W.A., Tan, A.-C., Vikhraman, M., 2013. Antimicrobial agents for food packaging applications. Trends Food Sci. Technol. 33, 110-123.

U.S. 2017. Substances Generally Recognized as Safe. Essential oils, oleoresins (solventfree), and natural extractives (including distillates). Code of Federal Regulations. Title 21, Volume 3, Part 182, Section 182.20.

Vasilijević, B., Knežević-Vukčević, J., Mitić-Ćulafić, D., Orčić, D., Francišković, M., SrdicRajic, T., Jovanović, M., Nikolić, B., 2018. Chemical characterization, antioxidant, genotoxic and in vitro cytotoxic activity assessment of Juniperus communis var. saxatilis. Food Chem. Toxicol. 112, 118-125.

Vichy, S., Riu-Aumatell, M., Mora-Pons, M., Guadayol, J.M., Buxaderas, S., LópezTamames, E., 2007. HS-SPME coupled to GC/MS for quality control of Juniperus communis L. berries used for gin aromatization. Food Chem. 105, 1748-1754.

Yarnell, E., 2002. Botanical medicines for the urinary tract. World J. Urol. 20, 285-293. 